\title{
Fonksiyonel Ambliyopilerde Tedavi Yöntemlerinin Karşılaştırılması
}

\section{Comparison of Treatment Methods in Functional Amblyopies}

Selim Genç ${ }^{1}$

Ömer Kamil Doğan ${ }^{1}$

${ }^{1}$ Istanbul Kartal Dr. Lütfü Kırdar Eğitim ve Araştırma Hastanesi, Istanbul, Türkiye

Geliş Tarihi/Received: 15 Haziran 2020 Kabul Tarihi/Accepted: 1 Eylül 2020

Yazışma Adresi: Selim Genç, SBÜ Beyoğlu Göz Eğitim ve Araştırma Hastanesi, İstanbul, Türkiye

e-posta: gencselim@hotmail.com

\section{ORCID}

Selim Genç

https://orcid.org/0000-0003-3049-2571

Ömer Kamil Doğan

https://orcid.org/0000-0002-9459-051X
Öz

Amaç: Ambliyop hastalarda tam gün kapama, minimal kapama ve Cambridge görme uyaranı (CAM) tedavisinin görme keskinliği üzerine etkilerini karşılaştırmak

Hastalar ve Yöntem: Çalışmada fonksiyonel ambliyopisi olan 95 hasta yaş ve başlangıç görme keskinlikleri anlamlı farklılık oluşturmayacak şekilde üç gruba ayrıldı. Birinci gruba CAM tedavisi alanlar, ikinci gruba tam gün kapama yapılanlar, üçüncü gruba ise minimal kapama yapılanlar alındı. Takip süresi altı aydan az olanlar çalışmadan çıkarıldı. Hastaların görme keskinliğindeki artışları gruplar arasında karşılaştırıldı. Ayrıca katılımcılar foveal fiksasyonun olup olmaması, ambliyopi nedeni ve yaşa göre de sınıflandırıldı ve görme keskinliği değişimleri bu sınıflamalara göre de karşılaştırıldı.

Bulgular: CAM tedavisi alan 31 hasta, tam kapama yapılan 30 hasta ve minimal kapama yapılan 34 hasta çalışmada yer aldı. Grupların yaş ortalaması sırasıyla $5,50 \pm 2,05 ; 5,96 \pm 1,59$ ve $6,57 \pm 2,31$ idi $(p=0,105)$. CAM tedavi grubunda tedavi öncesi $0,45 \pm 0,28$ logMAR olan ortalama görme keskinliği tedavi sonrasında $0,31 \pm 0,25$ logMAR olurken, tam kapama yapılan grupta $0,50 \pm 0,16 \log M A R$ 'dan 0,27 $\pm 0,16 \log M A R ' a$, minimal kapama yapılan grupta ise $0,52 \pm 0,25 \log M A R ' d a n 0,30 \pm 0,21 \log$ MAR'a yükseldi. Görme keskinliğindeki artıs tam kapama ve minimal kapama yapılan grup arasında anlamlı fark oluşturmazken $(p=0,944)$ her iki gruptaki artış CAM tedavisi alan gruptan daha fazlaydı ve fark istatistiksel olarak anlamlıydı. (tam kapama-CAM için $p=0,029$ ve minimal kapama-CAM için $p=0,032$ ). Tedavi sekillerine bakmaksızın tüm hastalar üzerinden çeşitli gruplamalar yapıldığında tedavi başarısı foveal fiksasyonu olanlar, ambliyopi sebebi sadece anizometropi olanlar ve tedavisi altı yaştan önce başlananlarda, oluşturulan karşı gruplara göre daha yüksek oldu (sırasıyla $p=0,004, p<0,021, p=0,002$ ). Sonuç: Bu çalışmadaki verilere göre CAM tedavisi ile karşılaştırıldığında kapama tedavileri ile daha başarılı sonuçlar elde edilmektedir.

Anahtar Kelimeler: Fonksiyonel ambliyopi, CAM tedavisi, tam kapama, minimal kapama

\section{Abstract}

Aim: To compare the effects of full-time patching, minimal patching and Cambridge visual stimulator (CAM) treatment on visual acuity in amblyopic patients.

Patients and Methods: Ninety five patients with functional amblyopia were divided into three groups so that age and initial visual acuity did not make any significant difference. Those who received CAM treatment in the first group, those who underwent full-time patching in the second group, and those who had minimal patching in the third group were included. Patients with a follow-up period of less than six months were excluded from the study. The increase in visual acuity of the patients were compared between the groups. In addition, the participants were classified according to presence of foveal fixation, cause of amblyopia and age, and these data were compared for all patients.

Results: 31 patients who received CAM treatment, 30 patients who underwent full-time patching and 34 patients who underwent minimal patching were included in the study. The mean age of the groups was $5.50 \pm 2.05 ; 5.96 \pm 1.59$ and $6.57 \pm 2.31$ respectively $(p=0.105)$. While the mean visual acuity was 0.45 $\pm 0.28 \log M A R$ before the treatment in the CAM treatment group, it was $0.31 \pm 0.25$ logMAR after the treatment. It was changed from $0.50 \pm 0.16 \log M A R$ to $0.27 \pm 0.16 \log M A R$ in the full-time patching group and it was increased from $0.52 \pm 0.25 \log M A R$ to $0.30 \pm 0.21 \log M A R$ in the minimal patching group. While the increase in visual acuity revealed no significant difference between the full-time patching and minimal patching groups $(p=0.994)$, the increase in both groups was more than the CAM treatment group and the difference was statistically significant. ( $p=0.029$ for full-time patching-CAM and $p=0.032$ for minimal patching-CAM). When various groupings were made with all patients regardless of treatment methods, these groups had more succesful results than opposing groups: those have foveal fixation, those with amlyopia casused by only anisometropia and those whose treatment was initiated before six years old. ( $p=0.004, p=0.021, p=0.002$, respectively)

Conclusion: According to the data in this study, more successful results are obtained with patching treatments than CAM treatment.

Key words: Functional amblyopia, CAM treatment, full-time patching, minimal patching
Atıf yapmak için: Genç S, Doğan OK. Fonksiyonel Ambliyopilerde Tedavi

Yöntemlerinin Karşılaştırılması. Selcuk Med J 2020;36(4): 319-324 Açıklama: Yazarların hiçbiri, bu makalede bahsedilen herhangi bir ürün,
aygıt veya ilaç ile ilgili maddi çıkar ilişkisine sahip değildir. Araştırma,
herhangi bir dışorganizasyon tarafından desteklenmedi. Yazarlar çalışmanın
birincil verilerine tam erişim izni vermek ve derginin talep ettiği takdirde
verileri incelemesine izin vermeyi kabul etmektedirler. 


\section{GíRiş}

Ambliyopi, nüfusun yaklaşık \% 1 - \% 5'inde görülen, çocuklardaki önlenebilir görme bozukluğunun en yaygın nedenidir $(1,2)$. Genel olarak fonksiyonel ambliyopi veya tembel göz, çocukluk veya bebeklik dönemindeki anormal görme gelişiminin neden olduğu, herhangi bir organik patoloji olmadan bir veya her iki gözde en iyi düzeltilmiş görme keskinliğinin normale (20/20) göre daha düşük olmasını ifade eder (3).

Görme işleminin olgunlaşmamış olması nedeniyle doğumda görme keskinliği (GK) zayıftır. Normal görsel gelişim için net retina görüntüleri, her iki gözde eşit görüntü netliği ve uygun oküler hizalama dahil olmak üzere uygun görsel uyarı gereklidir. Net retina görüntüleri görsel merkezlerin nöro gelişimini teşvik etmeye başladığı için, yaşamın ilk birkaç ayında hızla düzelir $(4,5)$. Ancak görsel gelişim 7 ila 8 yaşına kadar (duyarlı dönem) devam eder ve görsel gelişim için nöral plastisite geç çocukluk döneminde giderek azaldığı için (4-6) 7-8 yaştan önce bulanık retina görüntüsü ile anormal görsel uyarı veya iki gözün yanlış hizalanmasına yol açacak hastalıklar neticesinde normal görsel yol gelişimi kesintiye uğrar ve ambliyopiye neden olur. Bu durum hayat boyu devam eder (7). Anizometropi ve şaşılık iki ana ambliyojenik faktördür ve bazı çocuklarda anizometropi ile şaşılık ambliyopisi beraberdir (7). Bu nedenle, ambliyopi tedavisinde ilk aşama çocukta var olan refraksiyon kusurunun uygun gözlük ya da yöntemlerle rehabilite edilmesidir $(8,9)$.

Ambliyopiyi tedavi etmenin temel stratejisi, her bir göze net bir retina görüntüsü sağlamak ve tek gözün aşırı baskınlığını düzeltmektir. Temel tedavi yöntemleri, eğer varsa altta yatan organik hastalığın düzeltilmesini, uygun gözlüğün reçete edilmesini ve hassas görsel gelişim dönemi geçmeden baskın gözü kapama tedavisini içerir. Bir çok ambliyop hastada eksantrik fiksasyon ortadan kaldırılarak ve görsel kortekse daha kapsamlı sinaptik girdi sağlayarak normal veya normale yakın görme fonksiyonu etkili bir şekilde geri yüklenebilir $(10,11)$.

Ambliyopi tedavisinde kapamaya alternatif olarak penalizasyon tedavisi, pleoptik tedavi, Cambridge görme uyaranı (CAM) tedavisi ve farmakolojik ajanlar ile tedavinin yanı sıra aralıklı kapanan gözlük, algısal öğrenme ve ikili eğitim tedavileri vardır $(7,12)$. CAM tedavisi ile ilgili çalışmalar ve rapor edilen veriler sınırlıdır.

Bu çalışmanın amacı ambliyopisi olan hastalarda tam gün kapama, sınırlı saatlerde kapama ve CAM tedavisini, görme keskinliği üzerindeki etkilerini temel alarak karşılaştırmaktır.

\section{HASTALAR ve YÖNTEM}

$\mathrm{Bu}$ çalışmaya fonksiyonel ambliyopi teşhisiyle izlenen, görme keskinliği en az 0,1 olan ve daha önce ambliyopiye yönelik tedavi almamış çocuklar dahil edildi. Olguların seçiminde organik nedenli ambliyopiler ve altı aydan daha az takip süresi olanlar çalışma kapsamı dışında tutuldu. Çalışmaya alınacak aday katılımcılar ardışık olarak üç gruba ayrıldı. Yaş ve başlangıç görme keskinliği bakımından gruplar arası farklılık oluştuğu takdirde uçtaki değerlere sahip hastaların çalışmaya alınmaması planlandı. Birinci grupta CAM yöntemi uygulanan 31 kişi, ikinci grupta tam kapama yapılan 30 kişi, üçüncü grupta ise minimal kapama yapılan 34 kişi yer aldı.

Tüm hastaların tashihsiz görme keskinliği Snellen eşeli ile alındıktan sonra şaşılık muayenesi, biyomikroskop muayenesi, sikloplejik ölçüm ve detaylı fundus muayenesi yapıldı. Sonrasında bir hafta içinde gözlük reçeteleri oluşturuldu. Snellen eşeli ile alınan görme keskinliği değerleri logMAR'a çevrildi.

Tam gün total kapama için hastaların iyi gören gözü haftada altı gün süreyle tüm gün kapatılıp haftanın bir günü iki göz de açık bırakıldı. Her ay kontrol muayenesi yapılarak ölçümleri tekrarlandı. Minimal kapama için ise günde iki saat olacak şekilde haftanın yedi günü iyi gören göz kapatıldı. Hastaların kapama süresince resim yapmak, atari oynamak gibi yakın çalışma yapmaları gerektiği belirtildi.

CAM tedavisi alan hastalara tedavi haftada en az üç seans uygulandı. Her seansta çocuğun sağlam gözü kapatıldı ve renkli kalemlerle saydam plakalar üzerinde çizim oyunları oynarken aynı anda arka plandaki yüksek kontrastlı, dönüş hızı dakikada 1 devir olan, keskin kenarlı diskler tarafından görsel sistemin uyarılması sağlandı. Yedi değişik frekanstaki disklerden düşük frekanslı olandan başlandı ve her biri bir dakika olacak şekilde sırayla daha yüksek olana geçildi.

Hastaların ilk görmeleri refraksiyon kusuru düzeltildikten sonra kullanılan eşel belirtilerek kaydedilmiştir. Sonraki muayenelerde de aynı eşel kullanılmıştır.

Bulguların istatistiksel olarak değerlendirilmesinde Statistical Package for Social Sciences (SPSS, Chicago, IL, ABD) 20.0 sürümü kullanıldı. Başlangıçta Kolmogorov-Smirnov testi ile verilerin dağılımının normalitesi değerlendirildi. Sayısal veriler, dağıımı normal olanlarda ortalama \pm standart sapma, 
dağılımı normal olmayanlarda ise ortanca (minimum ve maksimum) olarak ifade edildi. Kategorik verilerin karşılaştırılmasında ki-kare testi kullanıldı. Sayısal veriler için ikiden fazla grup karşılaştırılırken ANOVA testi, iki grup karşılaştırılırken Student $T$ test yapıldı. Birden fazla gruplara ait verilerin tekrarlayan ölçümlerindeki değişiklikleri karşılaştırmak için karma desen ANOVA testi, post-hoc test olarak Bonferroni testi kullanıldı. İstatistiksel anlamlılık için $p<0.05$ değeri kabul edildi.

\section{BULGULAR}

Çalışmaya alınan hastalardan CAM tedavisi alanların 18'i $(\% 58,1)$ erkek, 13'ü $(\% 41,9)$ kadın iken beşinin $(\% 16,1)$ ambliyopi nedeni anizometropi, 26 'sının $(\% 83,9)$ ise ezotropyaydı. Hastaların 12'sinde $(\% 38,7)$ foveal fiksasyon mevcuttu. Yaş ortalaması $5,50 \pm 2,05$ idi.

Tam kapama tedavisi alan olguların 18'i $(\% 60,0)$ erkek, 12'si $(\% 40,0)$ kadındı. On $(\% 33,3)$ hastada anizometropi, 20 hastada ise $(\% 66,7)$ ezotropya saptandı. Hastaların 26'sında $(\% 86,7)$ foveal fiksasyon mecvuttu ve üç hastada fiksasyon noktası fovea dışındaydı. Yaş ortalaması 5,96 \pm 1,59 idi.

Minimal kapama tedavisi alanların 14'ü $(\% 41,2)$ erkek, 20'si $(\% 58,8)$ kadındı. On üç $(\% 38,2)$ hastada anizometropiye bağlı ambliyopi varken $21(\% 61,8)$ hastanın ambliyopi sebebi ezotropyaydı. Olguların 28 'inde $(\% 82,4)$ foveal fiksasyon vardı. Yaş ortalaması $6,57 \pm 2,31$ idi. Olguların demografik ve bazı klinik özellikleri tablo 1'de gösterilmiştir.

Gruplar arasında yaş ve başlangıç görme keskinliği açısından anlamlı bir fark yoktu (sırasıyla $p=0,105$ ve $\mathrm{p}=0,480)$.

Tüm gruplarda tedavi ile ambliyop gözün görme keskinliğindeki değişim istatistiksel olarak anlamlı olarak saptandı. CAM tedavi grubunda tedavi öncesi $0,45 \pm 0,28 \log$ MAR $(0,41 \pm 0,18$, Snellen $)$ olan ortalama görme keskinliği tedavi sonrasında 0,31 \pm $0,25 \log \operatorname{MAR}(0,55 \pm 0,26$, Snellen) olurken $(p<0,001)$ tam kapama yapılan grupta 0,50 $\pm 0,16$ logMAR'dan $(0,33 \pm 0,13$, Snellen) 0,27 $\pm 0,16$ logMAR'a $(0,55 \pm$ 0,20 , Snellen) $(p<0,001)$ ve minimal kapama yapılan grupta $0,52 \pm 0,25 \log M A R ' d a n(0,34 \pm 0,17$, Snellen) 0,30 \pm 0,21 logMAR'a $(0,54 \pm 0,22$, Snellen) yükseldi $(p<0,001)$. Gruplardaki görme keskinliği artış miktarları birbirleriyle karşılaştırıldığında gruplar arasında anlamlı fark saptandı $(p=0,012)$ (Tablo 2$)$.

Gruplar kendi aralarında ikili olarak karşılaştırıldığında tam kapama yapılan gruptaki artışın CAM grubuna göre daha fazla olduğu $(p=0,029)$, minimal kapama yapılan gruptaki yüzde artışın CAM grubuna göre (\% 43,49 $\pm 41,41)$ daha fazla olduğu $(p=0,032)$, minimal kapama grubu ile tam kapama yapılan grup arasında ise anlamlı fark bulunmadığı görüldü. $(p=0,944)$ (Tablo 3$)$. Snellen eşeliyle alınan ondalık görme keskinliğindeki yüzde artış ise CAM grubunda \% 43,49 $\pm 41,41$, tam kapama yapılan grupta $\% 83,08 \pm 90,16$ ve minimal kapama yapılan grupta ise $\% 75,92 \pm 57,14$ olarak saptandı.

Tüm hastalar tedavi türünden bağımsız olarak fiksasyonun foveal ya da ekstrafoveal olmasına göre gruplandırıldığında foveal fiksasyonu olanlarda görme keskinliği artışı daha fazla oldu $p=0,0214$ ). Ayrıca ambliyopi sebebinde ezotropya olanlar sadece anizometropi olanlara göre tedavilerden daha az fayda gördü $(p=0,004)$. Altı yaşından daha küçük hastaların da altı yaşında ya da daha büyük yaşta olanlara göre görme keskinliğindeki artışın daha fazla olduğu görüldü $(p=0,002)$ (Tablo 4).

\section{TARTIŞMA}

On sekizinci yüzyılda Buffon tarafından ortaya atılan ve sağlam gözün kapatılıp kayan gözün açık bırakılarak kayan gözdeki görmeyi artırmayı amaçlayan ambliyopi tedavisi fikri halen bu konuda en çok kullanılan tedavi yöntemidir $(13,14)$. Kapama tedavisinin etkinliğini araştıran birçok çalışma yapılmıştır.

Leiba et al. (15) başlangıçta ortalama görme keskinliği 0,90 logMAR (yaklaşık 20/158) ve yaş ortalaması 5,1 olan 54 hastaya tam kapama uygulamışlar, tedavi sonrası görme keskinliğini ortalama 7,4 yaşındayken 0,24 logMAR, ortalama 13,7 yaşında iken 0,35 logMAR ve ortalama 29,0 yaşındayken 0,24 logMAR (yaklaşık 20/35) olarak

Tablo 1. Hastaların demografik ve bazı klinik özellikleri

\begin{tabular}{|c|c|c|c|c|}
\hline Parametre & $\operatorname{CAM}(n=31)$ & Tam kapama $(n=30)$ & Minimal kapama $(n=34)$ & $\mathbf{p}$ \\
\hline Cinsiyet (E/K) & $18(\% 58,1)-13(\% 41,9)$ & $18(\% 60,0)-12(\% 40,0)$ & $14(\% 41,2)-20(\% 61,8)$ & $0,244^{*}$ \\
\hline Yaş $(y ı l)$ (Ort. $\pm S S)$ & $5,50 \pm 2,05$ & $5,96 \pm 1,59$ & $6,57 \pm 2,31$ & $0,105^{* *}$ \\
\hline Tanı (AÍ/ET $\pm A \mathrm{I})$ & $5(\% 16,1)-26(\% 83,9)$ & $10(\% 33,3)-20(\% 66,7)$ & $13(\% 38,2)-21(\% 61,8)$ & $0,111^{*}$ \\
\hline Fiksasyon noktası (F/EF) & $12(\% 38,7)-19(\% 61,3)$ & $26(\% 86,7)-4(\% 13,3)$ & $28(\% 82,4)-6(\% 17,3)$ & $<0,001^{*}$ \\
\hline
\end{tabular}


Tablo 2. Grupların görme keskinliği ve değişimlerinin karşılaştırılması

\begin{tabular}{|c|c|c|c|c|}
\hline Parametre & $\begin{array}{l}\text { CAM } \\
(n=31)\end{array}$ & $\begin{array}{l}\text { Tam kapama } \\
(n=30)\end{array}$ & $\begin{array}{l}\text { Minimal kapama } \\
(n=34)\end{array}$ & $\mathbf{p}$ \\
\hline Başlangıç GK (logMAR) (Ort $\pm S S)$ & $0,45 \pm 0,28$ & $0,50 \pm 0,16$ & $0,52 \pm 0,25$ & $0,480^{*}$ \\
\hline Son GK (logMAR) (Ort $\pm S S$ ) & $0,31 \pm 0,25$ & $0,27 \pm 0,16$ & $0,30 \pm 0,21$ & $0,695^{*}$ \\
\hline $\mathrm{p}$ & $<0,001^{* *}$ & $<0,001^{* *}$ & $<0,001^{* *}$ & \\
\hline Değişim (Ort $\pm S S$ ) & $0,14 \pm 0,12$ & $0,23 \pm 0,12$ & $0,22 \pm 0,15$ & $0,012^{* *}$ \\
\hline
\end{tabular}

GK: Görme keskinliği, SS: Standart sapma, *: One-Way ANOVA, ${ }^{* *}$ : Karma desen ANOVA test

saptamışlardır. Bowman et al. (16) 88 amliyopik göze sahip hastalara kapama tedavisini ortalama 4,1 yaşında başlamış, başlangıçta 0,47 logMAR (yaklaşık 20/60) olan görme keskinliğinin ortalama 7,5 yaşında iken 0,23 logMAR'a, ortalama 12,3 yaşında iken ise 0,18 logMAR'a (yaklaşık 20/30) çıktığını rapor etmişlerdir. Repka et al. (17) ise ortalama yaşı 5,1 olan ve ortalama başlangıç görme keskinliği 0,53 logMAR (yaklaşık 20/67) olan hastaların görme keskinliklerinin altı ay sonra 0,22 logMAR, iki yıl sonra 0,13 logMAR, on yaş kontrollerinde 0,16 logMAR, 15 yaş kontrollerinde ise 0,14 logMAR (yaklaşık 20/25) olarak ölçmüşlerdir. $\mathrm{Bu}$ çalışmalarda görme keskinliğindeki artış oranı yüzde yüz civarında görünmektedir.

Çalışmamızda tam kapama yapılan hastaların başlangıç yaşı 5,9, ambliyop gözlerinin başlangıç görme keskinliği ise ondalık olarak 0,32 (20/63) $(0,50$ logMAR) idi. Son muayenedeki görme keskinliği ise 0,55 (20/36) (0,27 logMAR) idi. Görme keskinliğindeki artış \%83 olup bu oran örnek olarak verilen yukarıdaki çalışmalardan daha düşüktür. Bunun sebebi başlangıç yaşının daha büyük olması ve takip süresinin kısalığı ile ilişkili olabilir.

Uzun bir süreç boyunca tam gün kapama yapmak çocuklar üzerinde fiziksel ve psikolojik stres

Tablo 3. Görme keskinliğindeki artışın tedavi grupları için karşılaştırılması

\begin{tabular}{ll}
\hline CAM-Tam kapama & $\mathrm{p}=0,029^{*}$ \\
CAM-Minimal kapama & $\mathrm{p}=0,032^{*}$ \\
Tam kapama-Minimal kapama & $\mathrm{p}=0,944^{*}$ \\
\hline${ }^{*}$ Karma desen ANOVA post-hoc test (Bonferroni) &
\end{tabular}

ortaya çıkarabilmektedir (13). Bu yüzden ambliyopi tedavisinin çocuklar ve aileleri üzerindeki olumsuz etkilerini en aza indirirken tam gün kapama ile benzer başarıyı sağlayacak günlük kapama saatini ortaya koymak için birçok çalışma yapılmıştır (1822). Bir PEDIG (Pediatric Eye disease invesitgator group) çalışmasında, ciddi ambliyopisi olan (20/100 - 20/400) 3 - 7 yaş arasındaki çocuklarda ambliyop gözün günde 6 saat kapanmasıyla elde edilen görme keskinliği iyileşmesi tam zamanlı kapamayla elde edilene benzer olarak sonuçlandı (18). Orta derecede ambliyopisi olan çocuklarda (20/40 - 20/80) ise günde 2 saat kapama tedavisi, günde 6 saatlik kapama ile sağlanan görme keskinliği artışına benzer bir sonuç verdi (19).

Çalışmamızda da başlangıç görme keskinlikleri istatistiksel olarak farklı olmayan iki gruptan tam kapama yapılan hastalarla günde iki saat kapama yapılan hastaların tedavi sonunda görme keskinliği artışı yönünden anlamlı fark bulunmadı.

Ambliyopi tedavisinde total kapama dışında tedavi yöntemlerinin alternatif bir yöntem olarak kullanılması, hem hekim hem de hasta tarafından uygulanılabilecek yöntemin tercihli olarak seçilebilmesi, ayrıca uzun süre tatbik edildikten sonra etkisi olmayan bir yöntemin yerine, başka bir yöntemle tedaviye devam edilebilmesine de olanak sağlamaktadır. Bu konuda alternatif olarak kullanılmış tedavilerden biri de CAM tedavisidir.

Campbell etal. (23) \%73, Willshaw et al. (24) \%73,8, Lennerstrand et al. (25) \%69,9 civarında başarılı sonuçlar bildirmiş olsalar da bu çalışmalardaki başarı kriterinin genelde görme keskinliğinde bir sıra artış şeklinde olması ve olgu sayılarının azlığı çalışmaların

Tablo 4. Tüm hastalardaki görme keskinliği değişiminin klinik özelliklere göre karşılaştırılması

\begin{tabular}{|c|c|c|}
\hline Anizometropi $(n=28)$ & Ezotropya \pm Anizometropi $(n=67)$ & $\mathbf{p}^{*}$ \\
\hline $0,26 \pm 0,17$ & $0,18 \pm 0,12$ & 0,004 \\
\hline Foveal $(n=66)$ & Ekstrafoveal $(n=22)$ & $\mathbf{p}^{*}$ \\
\hline $0,23 \pm 0,14$ & $0,15 \pm 0,13$ & 0,021 \\
\hline$\geq 6$ yaş $(n=46)$ & $<6$ yaş $(n=49)$ & $p^{*}$ \\
\hline $0,16 \pm 0,10$ & $0,24 \pm 0,16$ & 0,002 \\
\hline
\end{tabular}


bulgularının değerini kısıtlamaktadır. Nitekim CAM tedavisi ile ilgili bu ilk ümit verici sonuçlara rağmen, kontrollü çalışmalarda CAM tedavisinin geleneksel kapama tedavisine göre herhangi bir avantaj sağlamadığı bildirilmiştir $(24,26)$. Çalışmamızda da CAM tedavisi uygulanmış hastalarda görme keskinliğindeki artış başlangıçtaki görme keskinliğine göre \%43,49 olarak gerçekleşmiş olup bu artış oranı tam kapama tedavisi alan gruba göre anlamlı olarak daha azdır.

Ambliyopide tedaviye başlangıç yaşının önemi birçok çalışmada belirtilmiştir. Holmes et al. (27) yaptığı metaanalizde 7 - 13 yaş arasındaki denekler, orta ve şiddetli ambliyopide daha genç yaş gruplarına (3-5 yaş arası ve 5-7 yaş arası ) kıyasla tedaviye anlamlı derecede daha az yanıt verdiği gösterilmiştir. Orta derecede ambliyopi için ise 3 - 5 yaş ve 5 - 7 yaş arasındaki deneklerde tedavi yanıtı açısından fark saptanamamıştır $(P=0,67)$. Ancak şiddetli ambliyopide 5-7 yaş arası çocuklara kıyasla 3-5 yaş arası çocuklarda tedaviye yanıtın daha fazla olduğu görülmektedir $(P=0,09)$. Çalışmamızda ise altı yaştan önce tedavisine başlanmış çocukların altı yaş ve daha sonra başlananlara göre tedavilerden fayda görme oranı anlamlı olarak daha yüksek bulunmuştur. Tedaviyi etkileme potansiyeli bulunan parametrelerden diğer ikisi de ambliyopinin nedeni ve hastada foveal fiksasyonun olup olmamasıdır. Ambliyopi nedeni sadece anizometropi olanların şaşılığı olanlara göre tedaviden daha fazla fayda gördüğü birçok çalışmada bildirilirken (23-25) foveal fiksasyonlu hastalarda da eksantrik fiksasyonlu hastalara göre daha iyi sonuçlar elde edilmiştir (25). Çalışmamızda da foveal fiksasyonu olanlarda olmayanlara göre tedaviye yanıt daha iyi görülürken, ambliyopinin nedeni sadece anizometropi olanlar şaşılığı olanlara göre tedaviden daha fazla fayda görmüşlerdir.

Çalışmamızda elde ettiğimiz bulguları kısıtlayan bazı nedenler vardır. Bunlardan en önemlisi örneklem grubumuzun küçüklüğü bir diğeri ise takip süresinin kısalığıdır.

Sonuç olarak çalışmamızdaki verilere göre kapama tedavileri CAM tedavisine göre daha başarılı tedavi yöntemleri olarak görünmektedir. Daha büyük örneklem ve daha uzun süreli takiple yapılacak çalışmalar daha güçlü veriler sunacaktır.

Çıkar Çatışması: Çalışmada herhangi bir çıkar çatışması yoktur.

Finansal Çıkar Çatışması: Çalışmada herhangi bir finansal çıkar çatışması yoktur.
Yazışma Adresi: Selim Genç, Bereketzade Mahallesi SBÜ Beyoğlu Göz Eğitim ve Araştırma Hastanesi, 34421 Beyoğlu, Istanbul, Türkiye

Telefon: +905326136391

e-mail: gencselim@hotmail.com

\section{KAYNAKLAR}

1. Wallace DK, Repka MX, Lee KA, et al. Amblyopia preferred practice pattern®. Ophthalmol 2018;125(1):105.

2. Koçak G, Duranoğlu Y. Ambliyopi ve tedavisi. Turk Oftalmoloji Dergisi 2014;44(3):228-36.

3. Kantarcı FA. Ambliyopi olgularının yetişkin dönemdeki klinik özelliklerinin değerlendirilmesi. J Kartal TR 2015;26(3):2116.

4. Weinacht S, Kind C, Mönting JS, et al. Visual development in preterm and full-term infants: A prospective masked study. Invest Ophthalmol Vis Sci 1999;40(2):346-53.

5. Daw NW. Critical periods and amblyopia. Arch Ophthalmol 1998;116(4):502-5.

6. Gaier ED, Hunter DG. Advances in amblyopia treatment: Paradigm shifts and future directions. Int Ophthalmol Clin 2017;57(4):117-28.

7. Park SH. Current management of childhood amblyopia. Korean J Ophthalmol 2019;33(6):557-68.

8. Wong AM. New concepts concerning the neural mechanisms of amblyopia and their clinical implications. Can J Ophthalmol 2012;47(5):399-409.

9. Atilla $\mathrm{H}$, Erkam N. Comparison of anisometropes with and without amblyopia. Indian J Ophthalmol 2011;59(3):215-6.

10. Blakemore C, Van Sluyters RC. Reversal of the physiological effects of monocular deprivation in kittens: Further evidence for a sensitive period. J Physiol 1974;237(1):195-216.

11. Rauschecker J, W Schrader, Vongrunau M. Rapid recovery from monocular deprivation in kittens after specific visual training-a comparison of visually evoked-potentials and single unit responses. Clinical Vision Sciences 1987;1(3):257-68.

12. Güven $S$, Uzunel $D$, Köse $S$, et al. Ambliyopi tedavisinde CAM görme uyaranının etkinligi. T Oft Gaz 2007;37:149-55.

13. Kurt E, GündüzA, Akçam N, et al. Ambliyopi Tedavisinde CAM vision stimülatörün rolü. T Klinik Oftalmoloji 1997;6(3):162-4.

14. Watson PG, Sanac AS, Pickering MS. A comparison of various methods of treatment of amblyopia. A block study. Trans Ophthalmol Soc U K 1985;104(Pt 3):319-28.

15. Leiba $H$, Shimshoni $M$, Oliver $M$, et al. Long-term followup of occlusion therapy in amblyopia. Ophthalmology 2001;108(9):1552-5.

16. Bowman RJ, Williamson TH, Andrews RG, et al. An inner city preschool visual screening programme: Long-term visual results. Br J Ophthalmol 1998;82(5):543-8.

17. Repka MX, Kraker RT, Holmes JM, et al. Atropine vs patching for treatment of moderate amblyopia: Follow-up at 15 years of age of a randomized clinical trial. JAMA Ophthalmol 2014;132(7):799-805.

18. Holmes JM, Kraker RT, Beck RW, et al. A randomized trial of prescribed patching regimens for treatment of severe amblyopia in children. Ophthalmology 2003;110(11):207587.

19. Repka MX, Beck RW, Holmes JM, et al. A randomized trial of patching regimens for treatment of moderate amblyopia in children. Arch Ophthalmol 2003;121(5):603-11.

20. Pediatric Eye Disease Investigator Group. A randomized trial 
of near versus distance activities while patching for amblyopia in children aged 3 to less than 7 years. Ophthalmology 2008;115(11):2071-8.

21. Pediatric Eye Disease Investigator Group, Wallace DK, Lazar EL, et al. A randomized trial of increasing patching for amblyopia. Ophthalmology 2013;120(11):2270-7.

22. Wallace DK, Lazar EL, Crouch ER 3rd, et al. Time course and predictors of amblyopia improvement with 2 hours of daily patching. JAMA Ophthalmol 2015;133(5):606-9.

23. Campbell FW, Hess RF, Watson PG, et al. Preliminary results of a physiologically based treatment of amblyopia. $\mathrm{Br}$ J Ophthalmol 1978;62(11):748-55.

24. Willshaw HE, Malmheden A, Clarke J, et al. Experience with the CAM vision stimulator: Preliminary report. $\mathrm{Br} \mathrm{J}$ Ophthalmol 1980;64(5):339-41.
25. Lennerstrand G, Samuelsson B. Amblyopia in 4-yearold children treated with grating stimulation and fulltime occlusion; A comparative study. $\mathrm{Br} \mathrm{J}$ Ophthalmol 1983;67(3):181-90.

26. Tytla ME, Labow-Daily LS. Evaluation of the CAM treatment for amblyopia: A controlled study. Invest Ophthalmol Vis Sci 1981;20(3):400-6.

27. Holmes JM, Lazar EL, Melia BM, et al. Effect of age on response to amblyopia treatment in children. Arch Ophthalmol 2011;129(11):1451-7. 